\title{
Basic properties and weathering process of strong weathered granite
}

\author{
Xirong Niu ${ }^{\mathrm{i}, \text { iv) }}$, Yanfang Sun ${ }^{\mathrm{ii} \text {,iii) }}$, Yangping Yao ${ }^{\text {iv) }}$ and Jian Han ${ }^{\text {iv })}$ \\ i) Department of Civil Engineering, Shanxi University, 92, Wucheng Road, Taiyuan, China \\ ii) College of Architecture and civil engineering, Taiyuan University of Technology, 79, Yingzexi Street, Taiyuan, China. \\ iii) Key Lab of Highway Construction \& Maintenance Technology in Loess Region, 36, Xutanxi Street, Taiyuan, China. \\ iv) School of Transportation Science and Engineering, Beihang University, 37, Xueyuan Road, Beijing, China.
}

\begin{abstract}
Strong weathered granite is abundant in China and it is used extensively as a fill material. However, systematic research on this material is relatively less as compared to sedimentary type of soils like sand and clay. In this study, a series of laboratory tests were performed, including X-ray diffraction test, sieving test, liquid and plastic limit test, compaction test, and California bearing ratio (CBR) test, to study the basic characteristic of strong weathered granite. Specially, in order to evaluate the effects of clay content on the mechanical properties of the compacted weathered granite, the extra compaction test and CBR test were made by using samples with the five different clay contents of 4 , 8,10 , and $12 \%$ by weight. Results of the laboratory tests indicated that the clay content of $8 \%$ could be a good indicator to determine the compaction characteristics of weathered granitic with different clay contents. Thus, clay content of about $8 \%$ would be advantageous to the compaction rate of subgrade and the stability of roads. However, The California bearing ratio of strong weathered granite with clay content of about $4 \%$ is largest, $95 \%$. A preliminary relationship between weathering process parameters $(m, r)$ and burying granite depth $(h)$ was established to improve the understanding of weathering process and degree of this material. It is found in this research that as the depth $h$ of weathered granite increases, the geological year's parameter $m$ becomes smaller in a power function, but the geometric progression constants $r$ becomes larger in a power function.
\end{abstract}

Keywords: strong weathered granite, laboratory test, basic characteristic, weathering process

\section{INTRODUCTION}

Granite is a kind of igneous rocks which is formed by Magma in inside the earth, and the main components of igneous rocks are quartz, feldspar, mica and hornblende (Lu \& Sang, 2002).

Granite shows a full crystal grain structure, hard texture and uniform property, and high compressive strength (120-200MPa). Because feldspar and mica exist joints, the granite have three groups of primary joints, and because the expansion coefficient of quartz and feldspar is difference nearly doubled, the granite surface easily cracks in the process of expansion and contraction, so the granite, especially coarse grain structure granite, weathered easily (Wu et al., 2004). Granite is influenced by the long-term geological tectonic movement and climate changes in the special geographical environment. Because of the different physical and chemical properties of granite mineral composition, granite has been weathered in different degrees of weathering, and decomposed granitic soils are generally classified as weak weathering, weathering, strong weathering and residual (WCHEG, 2007).
Weathered granite cover more than $9 \%$ from the soil area of China (Cui et al., 2007). Ease of availability means that these soils are frequently used as construction materials such as back fill or highway subgrade materials as a result of the scarcity of better materials (Li, 2002; Guo, 2009; Yang, 2009; Xiao, 2010; Niu, 2013).

Some researchers have conducted a series of studies and have preliminarily understood the engineering characteristics of weathered granite (Lee, 1995; Ng, 2004; Ham, 2010). As mentioned above, weathered granite is produced by physical and chemical weathering. However, it is not so easy for engineers to determine the degree of weathering of these soils since so many factors are involved.

In this study, besides specific gravity test, X-ray diffraction test, sieving test, liquid and plastic limit test, and CBR test, a sires of compaction tests were carried out on clay-mixed strong weathered granite in order to clarify the influence of clay contents on their compaction behavior. The index of power function in this research can be used as evaluate the weathering degree of weathered granite. 


\section{PREPARATION OF SAMPLES}

The strong weathered granite used in this research was sampled from a site near Yunzhong Mount, a Branch of Luliang Mount, on the eastern outskirts of Xinzhou, Shanxi, China. The strong weathered granite was used in Xinbao (Xinzhou to Baode) highway subgrade. There were three color kinds of weathered granites in the field, including red brown, yellow brown and gray, shown in Fig. 1. The in situ dry unit weight and moisture content were $17.82-18.22 \mathrm{kN} / \mathrm{m}^{3}$ and $4.9-5.5 \%$ respectively.

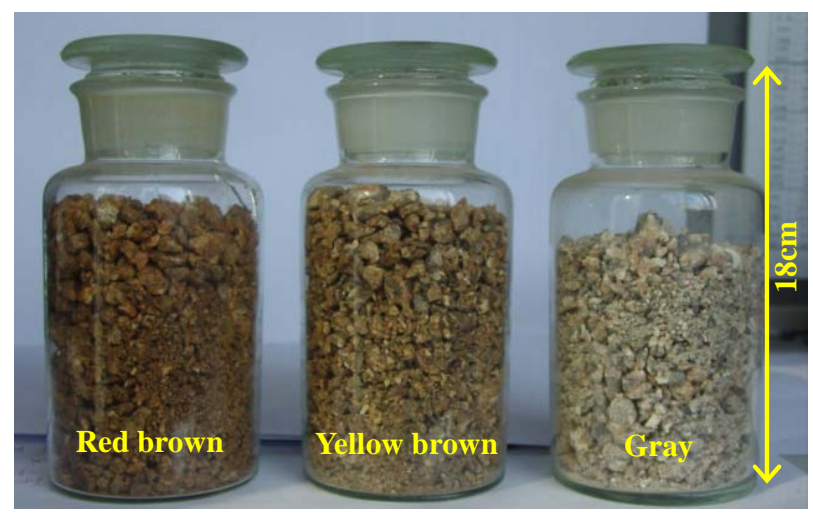

Fig. 1. Photograph of rock samples.

\section{BASIC CHARACTERISTICS OF WEATHERED GRANITIE}

\subsection{Specific gravity test}

The bottle method (T0112-1993, Test methods of soils for Highway Engineering) was used to acquire the specific gravity of weathered granite samples in this research. Through specific gravity test, it was found that the specific gravity of red brown, yellow brown and gray granite samples are $2.602 \mathrm{~g} / \mathrm{cm}^{3}, 2.636 \mathrm{~g} / \mathrm{cm}^{3}$ and $2.609 \mathrm{~g} / \mathrm{cm}^{3}$ respectively.

\section{$3.2 \mathrm{X}$-ray diffraction test}

The X-ray diffraction test is a classic analytical method on the mineral composition of soils and rocks. A X-ray diffraction equipment PSD-34 was used to analyze the primary mineral composition of strong weathered granite sample in this paper. According to the X-ray diffraction curve, the Joint Committee on Powder Diffraction Standards (JCPDS) Methods was adopted in this research.

Fig. 2 shows the the rock samples composition in this work. As can be seen from Fig. 1, the color of the samples becomes gradually shallow with the increase of the content of quartz, and the incremental content of potassium feldspar and plagioclase feldspar is the main cause that the rocks becomes light. Geng (2004) has claimed that the amphibole is blue green and the biotite is yellow in Yunzhong Mount, and that the main body of granite is coarse grain (porphyritic granite), while fine grained granite on the edge. The three kinds of samples used in this research had quart (mean 40.3\%) and feldspar (mean 54.3\%) as the dominant minerals present, with smaller amounts of mica (mean 1.3\%), amphibole (mean $2 \%$ ), haematite $(0.5 \%)$, vermiculite $(1 \%)$ and unknown (1\%).

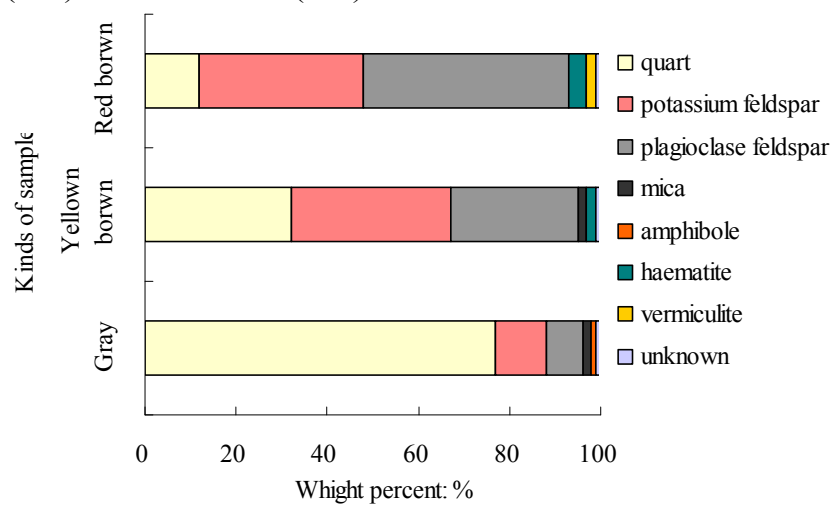

Fig. 2 Mineral composition of weathered granite samples

\subsection{Sieving test and liquid and plastic limit test}

Fig. 3 shows the differences of measured particle size distribution through sieving tests on the previous three different samples. Table 1 shows the uniformity coefficient $\left(C_{\mathrm{u}}\right)$ and curvature coefficient $\left(C_{\mathrm{c}}\right)$ of the samples tested in the study. According to the test methods of soils for Highway Engineering (JTG E40-2007), when the uniformity coefficient of coarse grained soil is greater than or equal to 5 and the curvature coefficient is equal to 1-3, it is a good gradation. It is can be found from Fig. 3 and Table 1 that the red brown is finest and the gray coarsest, and the gradation of red brown is best and the gray worst.

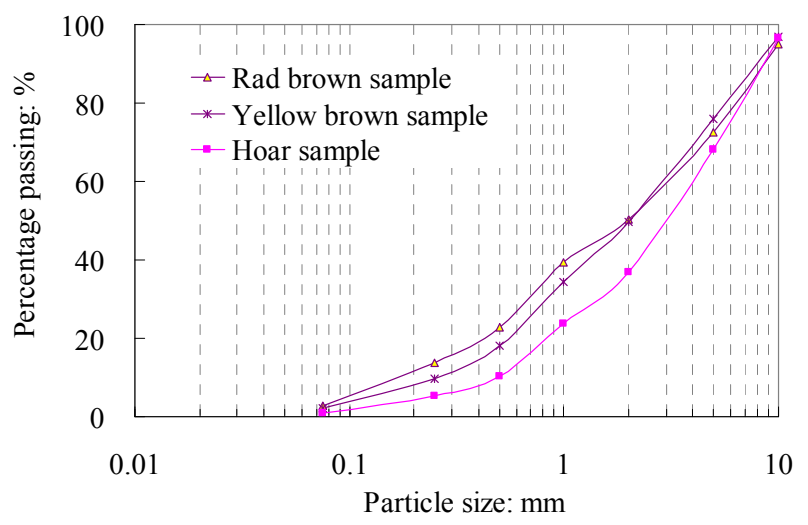

Fig. 3. Compaction curves for the soils with different clay content

Table 1. $C_{\mathrm{u}}$ and $C_{\mathrm{c}}$ of weathered granite samples

\begin{tabular}{llllll}
\hline Styles of samples & $d_{10}(\mathrm{~mm})$ & \multicolumn{2}{l}{$d_{30}(\mathrm{~mm})$} & $d_{60}(\mathrm{~mm}) C_{\mathrm{u}}$ & $C_{\mathrm{c}}$ \\
\hline Red brown & 0.15 & 0.6 & 2.3 & 15.33 & 1.04 \\
\hline Yellow brown & 0.22 & 0.81 & 2.9 & 13.18 & 1.03 \\
\hline Gray & 0.5 & 1.2 & 4 & 8.00 & 0.72 \\
\hline
\end{tabular}

A Liquid Plastic Combine Tester was used in this research to obtain the liquid limit and plastic limit index of red brown strong weathered granite. The results of liquid and plastic limit test showed that the liquid limit, the plastic limit and the plasticity index of red brown weathered granite are $32.8 \%, 23.5 \%$ and 9.2 
respectively.

\subsection{Compaction test}

On the basis of Test methods of soils for Highway Engineering (JTG E40-2007), the heavy compaction test method was used in the three color kinds of typical samples. Through this test, it was found that the maximum dry density (MDD) of pure red brown sample, yellow brown sample and gray sample are $2.13 \mathrm{~g} / \mathrm{cm}^{3}, 2.25 \mathrm{~g} / \mathrm{cm}^{3}$ and $2.18 \mathrm{~g} / \mathrm{cm}^{3}$ respectively. The maximum dry densities of finer red brown sample and the coarser gray sample are smaller than that of yellow brown sample, this is because that the compaction character of weather gratin is synthetically effected on the size distribution of soils, the hardness degree rock and the the degree of weathering.

The weathering granite stratum was covered by Pleistocene $\left(\mathrm{Q}_{3}\right)$ and Pleistocene $\left(\mathrm{Q}_{4}\right)$ Loess Holocene in the surrounding of Xinbao highway. In the process of filling subgrade, specially shovelling and transport weathering material, it is inevitable that the clay in situ will be mixed into the weathering filling material. In order to understand the characteristic of the weathering granite mixed with different clay content, the heavy compaction tests were made by using samples with the five different clay contents of $4,8,10$, and $12 \%$ by weight. These clay samples were obtained from Xinzhou (Shanxi, China), which liquid limit and plasticity index are $33.2 \%$ and $15.5 \%$ respectively.

Gray weathered granite locate at depths of more than $30 \mathrm{~m}$ in the earth, but red brown and yellow brown weathered granite is at depths of less than $30 \mathrm{~m}$. The filling materials used for subgrade constriction are mainly obtained at depths of less than $30 \mathrm{~m}$, so the heavy compaction test been aimed at red brown and yellow brown samples. Fig. 4 shows the compaction curves for red brown and yellow brown samples with different clay content.

It can be seen from Fig. 4 that the peak MDD value occurs most significantly in the range of about $7.5 \%-10 \%$ fine aggregate content. The results of test clearly show also that as clay content increases, the MDD tends to be considerably reduced after it reaches the peak MDD. The MDD of red brown and yellow brown weathered granite is separately $2.32 \mathrm{~g} / \mathrm{cm}^{3}$ and $2.38 \mathrm{~g} / \mathrm{cm}^{3}$. Furthermore, the clay content relative to peak MDD of red brown is $1 \%$ larger than that of yellow brown.

In addition, the higher the clay content, the larger the optimum moisture content, this relationship is approximately linear. These results also indicate that because the gradation of red brown samples is finer than yellow brown, the optimum moisture content (OMC) of red brown samples is $0.1 \%$ smaller than yellow brown. It is noted that tendency to OMC increase slowed down slightly in the samples with more than $8 \%$ of clay content.

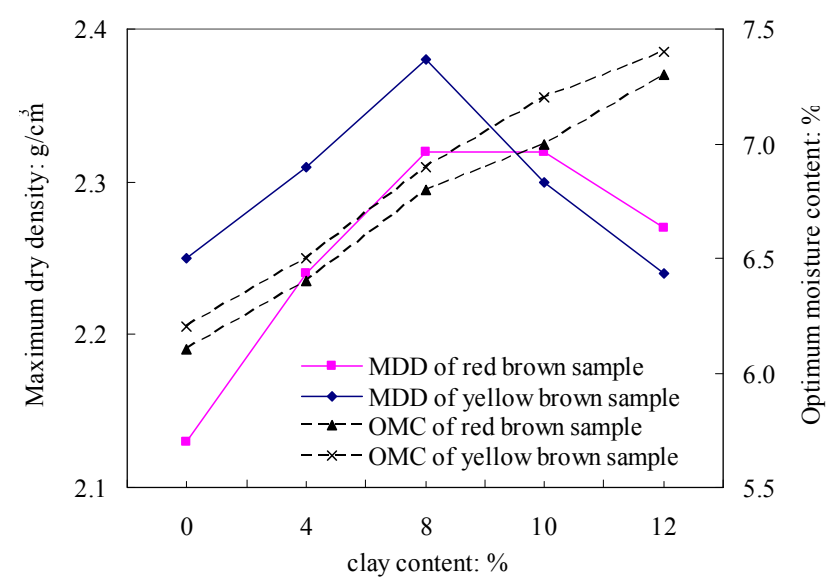

Fig. 4. Compaction curves for weathered granite samples with different clay content

\subsection{California bearing ratio (CBR) test}

Because the red brown strong weathered granite is most widespread in the field, the CBR test was carried out for the red sample in the field. Fig. 5 represents the relationship of clay content and $\mathrm{CBR}$ obtained from different compaction times test, which times are separately 30, 50 and 98. As seen in Fig. 5, the CBR come to a peak value when the compaction times are 50 or 98 . Because the compaction power under 30 times is not enough to make the rock in a dense state, the CBR of sample of 30 compact times don't arise a peak value. But, with increasing clay content, the sample of compaction 30 times will eventually arise a peak CBR. The experimental results shows, with the increase of compaction times, the peak value of CBR is on the increase. But, as the compaction times increase, the clay content at the point of peak CBR decreases. It is noted that the clay content at the point of peak CBR in 98 compact times is approximately $4 \%$, which is $4 \%$ less than the clay content at the point of peak maximum dry density. The cause of the above results is mainly that when clay content exceeds a certain value (such as $4 \%$ ), the interlocking structure of compacted weathered granite was opened by the clay in samples, the internal friction angle $(\varphi)$ was decreased, and the penetration resistance subsequently declined. Finally, the clay content at the point of peak CBR is larger than that at the point of peak maximum dry density.

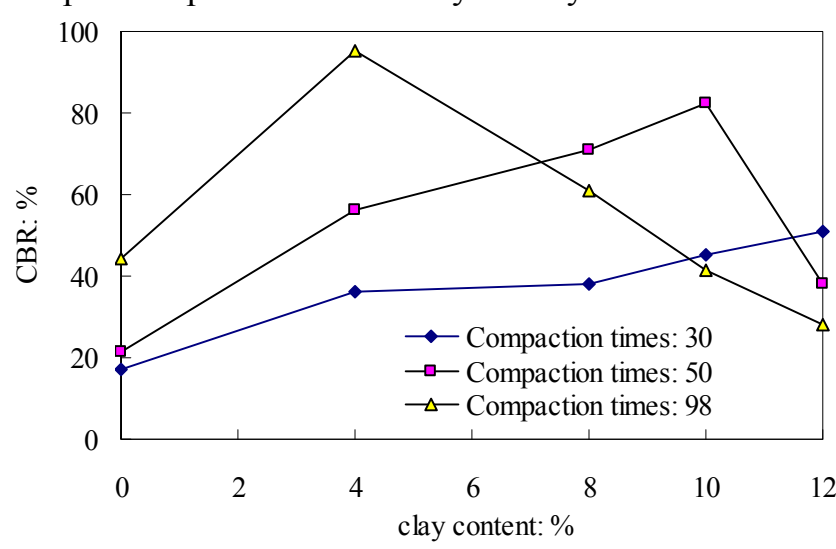

Fig. 5. Compaction curves for the soils with different clay content 


\section{WEATHERING PROCESS OF GRANITIE}

\subsection{Weathering model}

It is difficult to describe quantificationally the weathering process of granite by a certain mathematical model. Fukumoto (1990), in Ritsumeikan University, Japan, through some assumptions and simplifications, makes it possible to describe the process of granite weathering by mathematical methods. Based on a large number of field investigation and a series of sieving tests, Fukumoto (1990) has proposed a grad equation for decomposed grante soil through geometric fractal theories and mathematical statistics method, and has used it to evaluate the particle breakage of weathering rock. Afterwards, many researchers have achieved fruitful achievements by Fukumoto's model, so this research also uses this model to express the weathering process of granite. Before establishing weathering mathematical model, Fukumoto (1990) has made the following assumptions:

(1) In a state of weathering, the retained percentage of soil show statistically geometric progressional distribution, it is constant $r(0 \leq r \leq 1)$.

(2) The decomposed granite soil, which passed geological time of $y_{0}$ years, was sieved by one series of sieves with sieve ratio of $\lambda$.

(3) The percent retained of nth sieve from maximum grain size $D_{\max }$ toward smaller size, is expresses as $(1-r) \cdot r^{\mathrm{n}-1}$.

Eq. (1) and Eq. (2) are called a grading equation of decomposed granite soil in Fukumoto's paper (1990).

$$
\begin{gathered}
p_{n}=1-\sum_{i=0}^{n-1} C_{m+i-1}^{m-1}(1-r)^{m} \cdot r^{i} \\
n=\frac{\log \left(\frac{D_{\max }}{D_{n}}\right)}{\log \lambda}
\end{gathered}
$$

in which, $p_{\mathrm{n}}$ is the percent passing which pass mesh opening $D_{\mathrm{n}} . n$ in Eq. (1) is related with $D_{\mathrm{n}}$ as in Eq. (2).

The calculation steps of Fukumoto's equation are follows as:

(1) The position of $n$ on the horizontal axis in Fig,6 must be determined. Applying $D_{\max }$, the maximum grain size by actual measurement, and $\lambda=\sqrt[4]{2} \approx 1.189$, the sieve ratio assuming Tyler Series, $n=13.2877 \cdot \log \left(D_{\max } / D_{n}\right)$ is obtained from Eq. (3).

Using this relation and combining with grain size $D_{\mathrm{n}}$ on the horizontal axis, graduation of $n$ scale in figure is possible. Depending on the $n$ scale, read the value of percent passing $p_{\mathrm{n}}$ on vertical axis corresponding to integer $\mathrm{n}$ (dotted line in figure). Then, obtain the percent retained $q_{\mathrm{n}}$.

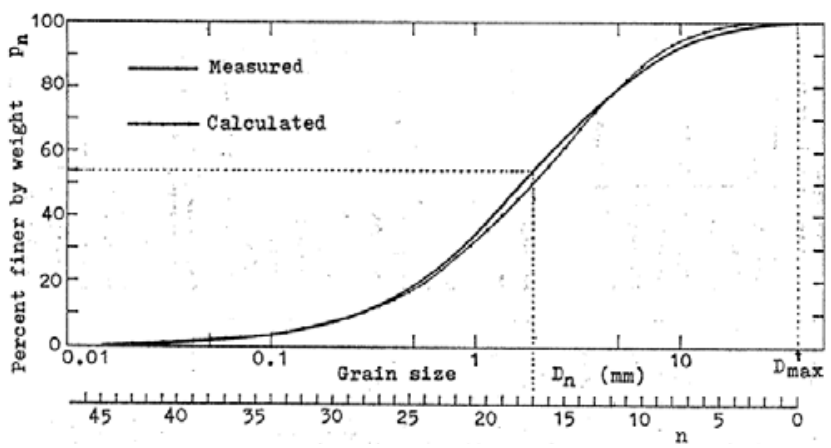

Fig. 6 Fitting of grading equation (after Fukumoto, 1990)

(2) Obtain mean $\mu$ and variance $\sigma^{2}$ by the following equation

$$
\begin{gathered}
\mu=\frac{\sum q_{n} \cdot n}{\sum q_{n}} \\
\sigma^{2}=\frac{\sum q_{n} \cdot(n-\mu)^{2}}{\sum q_{n}}
\end{gathered}
$$

Since Eq. (5) and Eq. (6) stand, $m$ and $r$ are obtained by Eq. (7) and Eq. (8).

$$
\begin{aligned}
\mu & =\frac{m r}{1-r} \\
\sigma^{2} & =\frac{m r}{(1-r)^{2}} \\
r & =1-\frac{\mu}{\sigma^{2}} \\
m & =\frac{\mu^{2}}{\sigma^{2}-\mu}
\end{aligned}
$$

Using Eq. (1) and Eq. (2) by the substitution of $m$ and $r$, the theoretical curve which is indicated by thin line in Fig. 6 is obtained.

\subsection{Field sampling and testing}

In order to evaluate the degree of weathering of granite, Fukumoto's weathering model was used in this research. Based on the thorough investigation on the distribution of weathered granite in the field (as shown in Fig. 7 and Fig. 8), a series of sieving testes were made on a large number of granite samples obtained from two typical sections, and geological year's parameter $m$ and geometric progression constants $r$ of different depth granite samples were calculated by Fukumoto's grading equation.

\subsection{Mathematical description of weathering process}

Fig. 9, Fig. 10, Fig. 11 and Fig. 12 illustrate the change of parameters $m$ and $r$ for different depth samples in section A and B. Results of the statistical analysis showed that there is a power function relationship between depth of samples and parameters $m$ (or $r$ ), and the correlation of relationship is relatively good. The power function relationships in section A are showed as follows:

$$
\begin{aligned}
m_{1} & =3.324 h^{-0.706} \\
r_{1} & =0.243 h^{0.153}
\end{aligned}
$$


where $h$ is the depth of granite samples, which is measured from the surface of mount; $m_{1}$ and $r_{1}$ is geological year's parameter and geometric progression constants in section A, respectively.

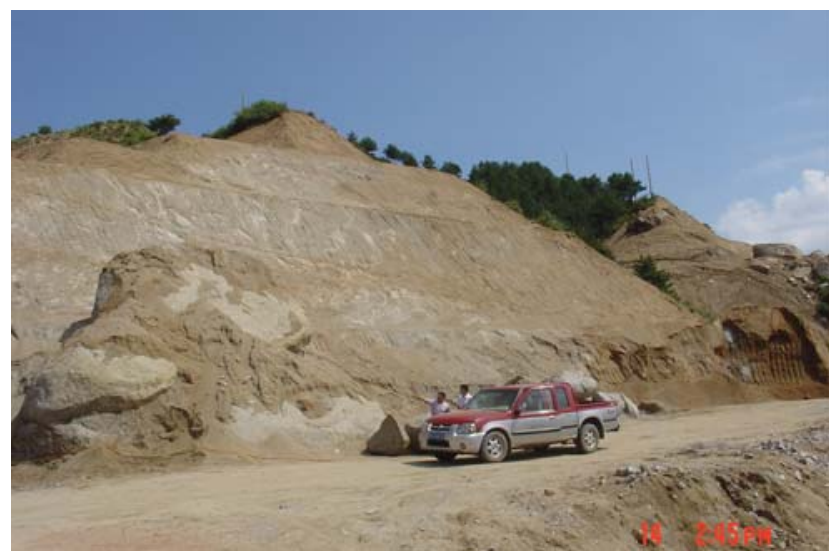

Fig. 7. Photograph of section A (Yellow brown)

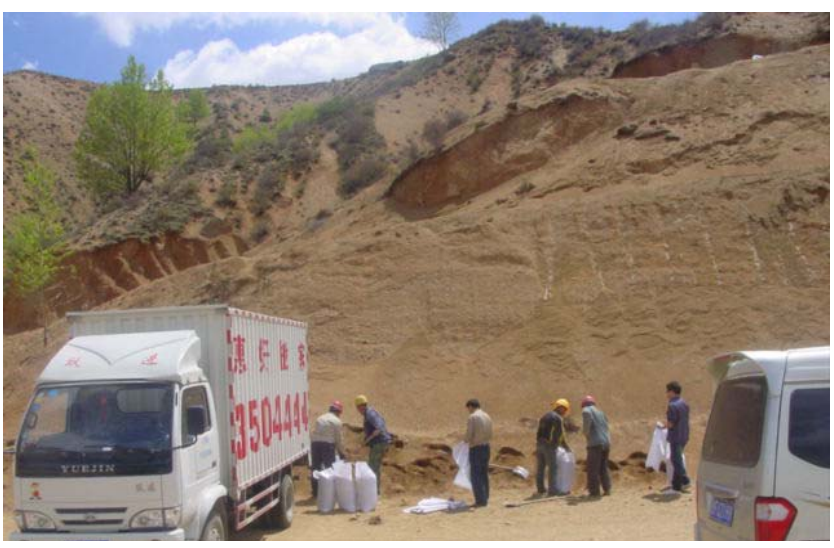

Fig. 8. Photograph of section B (Red brown)

The power function relationships in section $\mathrm{B}$ are showed as follows:

$$
\begin{aligned}
& m_{2}=3.729 h^{-0.747} \\
& r_{2}=0.269 h^{0.168}
\end{aligned}
$$

where $m_{1}$ and $r_{1}$ is geological year's parameter and geometric progression constants in section $\mathrm{B}$, respectively.

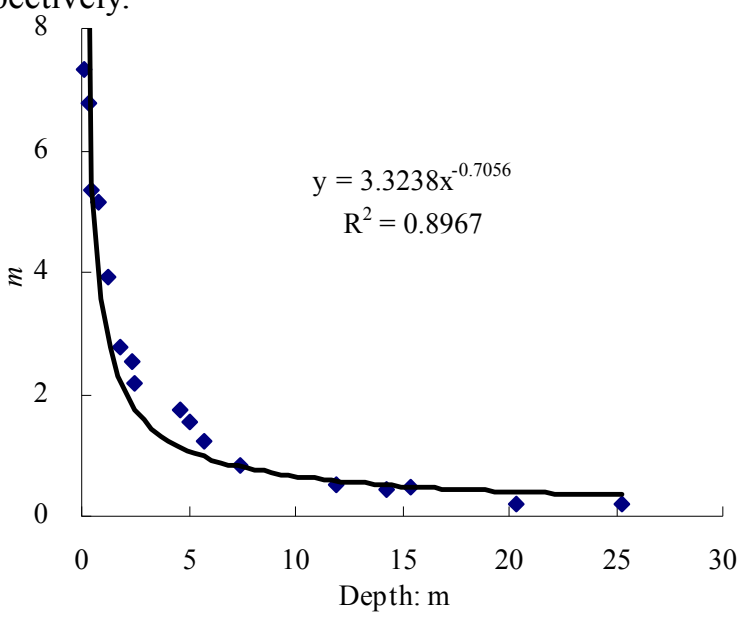

Fig. 9. Change of parameters $m$ for different depth samples in section $\mathrm{A}$

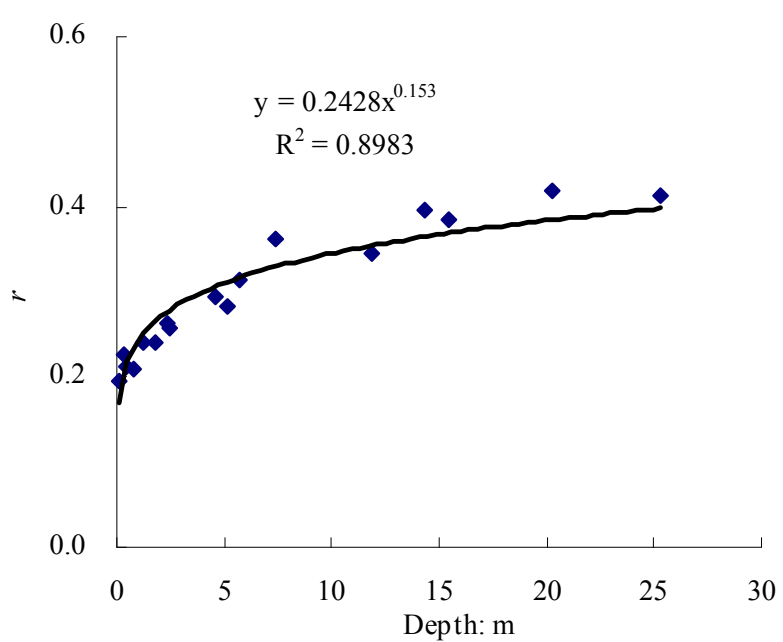

Fig. 10. Change of parameters $r$ for different depth samples in section $\mathrm{A}$

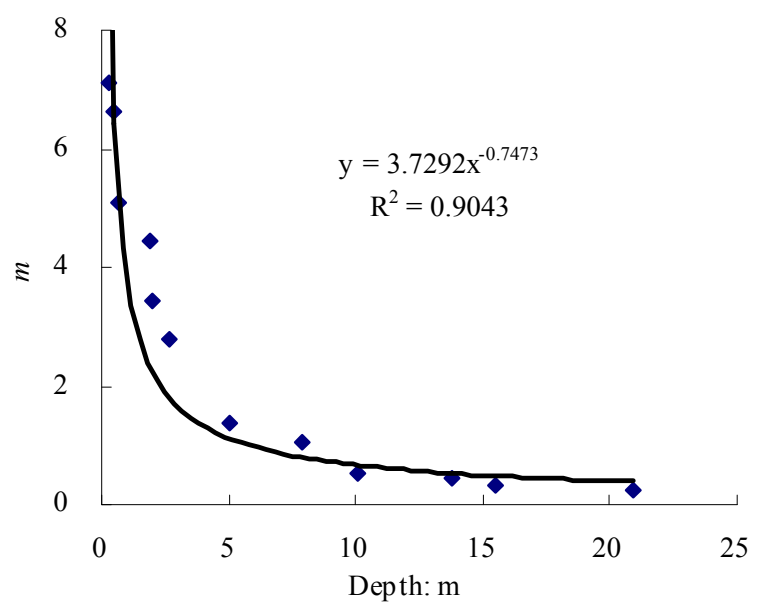

Fig. 11. Change of parameters $m$ for different depth samples in section $\mathrm{B}$



Fig. 12. Change of parameters $r$ for different depth samples in section B

\section{CONCLUSIONS}

In this study, specific gravity test, X-ray diffraction test, sieving test, liquid and plastic limit test, 
compaction test, and CBR test were conducted to investigate the basic physical and mechanical characteristic of strong weathered granite. The geological year's parameter $m$ and geometric progression constants $r$ of different depth granite samples in two typical sections were calculated by Fukumoto's grading equation. The main conclusions obtain from this study are summarized below.

(1) The major cause that the color of the strong weathered granite becomes light is the increase in the content of quartz. Also, the increase in the content of potassium feldspar and plagioclase make the color of weathered granite become dark.

(2) The pure strong weathered granite show similar compaction characteristics of sands. Characteristics of compression of the decomposed granitic vary significantly at the clay content of about $8 \%$. This indicates that the clay content of $8 \%$ can be a good indicator to determine the compaction characteristics of weathered granitic with different clay contents. Thus, clay content of about $8 \%$ would be advantageous to the compaction rate of subgrade and the stability of roads.

(3) The California bearing ratio of typical weathered granite is $15-50 \%$, and it can meet the requirements of subgrade bearing capacity, and the strong weathered granite in this study can be used as the filling of highway subgrade. The clay content is about $4 \%$ CBR value of the largest, up to $95 \%$. The California bearing ratio of strong weathered granite with clay content of about $4 \%$ is largest, $95 \%$.

(4) As the depth $h$ of weathered granite increases, the geological year's parameter $m$ becomes smaller in a power function, but the geometric progression constants $r$ becomes larger in a power function. The index of power function in this research can be used as evaluate the weathering degree of weathered granite.

\section{ACKNOWLEDGEMENTS}

The joint financial support provided by the Fundamental Research Funds for the Central Universities of Chang'an University (310821151111) and the Key Lab of Highway Construction \& Maintenance Technology in Loess Region of Shanxi Transportation Research Institute (KLTLR-Y12-9) is greatly appreciated.

\section{REFERENCES}

1) Cui, Z., Yang, J. and Chen, Y. (2007): The type and evolution of the granite landforms in China, ACTA Geographica SINICA, 62(7), 675-690 (in Chinese).

2) Fukumoto, T. (1990): A grading equation for decomposed granite soil, Soils and Foundations, 1990, 30(1), 27-34.

3) Geng, Y., Yang, C., Song, B. and Wan, Y. (2004): Post-orogenic granites with an Age of $1800 \mathrm{Ma}$ in Luliang area, north China craton: constraints from isotopic geochronology and geochemistry, Geological Journal of China Universities, 10(4), 477-487 (in Chinese).

4) Guo, N., Wang, X. and Zhao, Y. (2009): Mix design of granite stone mastic asphalt (SMA) mixture, Journal of
Building Materials, 12(2), 197-200 (in Chinese).

5) Ham, T., Nakata, Y., Orense, R. P. and Hyodo, M. (2010): Influence of gravel on the compression characteristics of decomposed granite Soil, Journal of Geotechnical and Geoenvironmental Engineering, 136(11), 1574-1577.

6) Lee, I. K. and Coop, M. R. (1995): The intrinsic behaviour of a decomposed granite soil, Geotechnique, 45(1), 117-130.

7) Li, J. and Tang, Y. (2002): Experiment study of modifying roadbed filler of seriously weathered granite by blending lime and technological process of construction, Journal of Hunan University (Natural Sciences Edition), 29(3), 161-167 (in Chinese).

8) Lu, F. and Sang, L. (2002): Petrology, ISBN 7-116-03506-0, Beijing: Geological Publishing House (in Chinese).

9) Ng, C. W., Fung, W. T., Cheuk, C. Y, and Zhang, L. (2004): Influence of stress ratio and stress path on behavior of loose decomposed granite, Journal of Geotechnical and Geoenvironmental Engineering, 130(1), 36-44.

10) Niu, X. (2013): Study on mechanical properties and subgrade filling technology of strongly weathered granite, $\mathrm{Ph} . \mathrm{D}$ thesis, Chang' an University, Xi' an (in Chinese).

11) The Writing Committee of Handbook of Engineering Geology (WCHEG). (2007): Handbook of Engineering Geology, ISBN 978-7-112-08828-7, Beijing: China Building Industry Press (in Chinese).

12) Wu, N., Zhao, C. and Hou, W. (2004): Research on the cause of formation, distribution and engineering characteristics of the granite residual soil, Journal of Pingdingshan Institute of Technology, 13(4), 1-4 (in Chinese).

13) Xiao, H., Jiang, G. and Wang, J. (2010): Experimental research on settlement of railway embankment on deep layer completely decomposed granite foundation based on centrifugal model test, Journal of Highway and Transportation Research and Development, 27(8), 40-44 (in Chinese)

14) Yang, W. (2009): Research on application of weathered granite material road performance, Ph.D thesis, Chang'an University, Xi' an (in Chinese). 